\title{
Impact of large solar zenith angles on lower stratospheric dynamical and chemical processes in a coupled chemistry-climate model
}

\author{
D. Lamago ${ }^{1,}{ }^{*}$, M. Dameris ${ }^{1}$, C. Schnadt ${ }^{1}$, V. Eyring ${ }^{1}$, and C. Brühl ${ }^{2}$ \\ ${ }^{1}$ Institut für Physik der Atmosphäre, DLR-Oberpfaffenhofen, D-82234 Wessling, Germany \\ ${ }^{2}$ Max-Planck-Institut für Chemie, D-55020 Mainz, Germany \\ *now at: ZWE FRM-II and Institut für Experimentalphysik E21, TU-München, D-85748 Garching, Germany
}

Received: 4 June 2003 - Published in Atmos. Chem. Phys. Discuss.: 22 July 2003

Revised: 25 October 2003 - Accepted: 29 October 2003 - Published: 12 November 2003

\begin{abstract}
Actinic fluxes at large solar zenith angles (SZAs) are important for atmospheric chemistry, especially under twilight conditions in polar winter and spring. The results of a sensitivity experiment employing the fully coupled $3 \mathrm{D}$ chemistry-climate model ECHAM4.L39(DLR)/CHEM have been analysed to quantify the impact of SZAs larger than $87.5^{\circ}$ on dynamical and chemical processes in the lower stratosphere, in particular their influence on the ozone layer.

Although the actinic fluxes at SZAs larger than $87.5^{\circ}$ are small, ozone concentrations are significantly affected because daytime photolytic ozone destruction is switched on earlier, especially at the end of polar night the conversion of $\mathrm{Cl}_{2}$ and $\mathrm{Cl}_{2} \mathrm{O}_{2}$ into $\mathrm{ClO}$ in the lower stratosphere. Comparing climatological mean ozone column values of a simulation considering SZAs up to $93^{\circ}$ with those of the sensitivity run with SZAs confined to $87.5^{\circ}$ total ozone is reduced by about $20 \%$ in the polar Southern Hemisphere, i.e., the ozone hole is "deeper" if twilight conditions are considered in the model because there is about 4 weeks more time for ozone destruction. This causes an additional cooling of the polar lower stratosphere $(50 \mathrm{hPa})$ up to $-4 \mathrm{~K}$ with obvious consequences for chemical processes. In the Northern Hemisphere the impact of large SZAs cannot be determined on the basis of climatological mean values due to the pronounced dynamic variability of the stratosphere in winter and spring. This study clearly shows the necessity of considering large SZAs for the calculation of photolysis rates in atmospheric models.
\end{abstract}

\section{Introduction}

Chemistry-climate links have received increased attention in recent years (IPCC, 2001; EC, 2003; WMO, 2003). The in-

Correspondence to: M. Dameris

(Martin.Dameris@dlr.de) vestigation of mutual effects of dynamical, chemical, and radiative coupling in the Earth's atmosphere is currently an outstanding scientific issue. Improved knowledge is necessary to better understand the relations between changes in atmospheric composition and climate. One key question, for example, is to which extent the recent destruction of the ozone layer has been affected by radiative cooling of the stratosphere due to increased greenhouse gas concentrations and how this will influence future ozone recovery.

Fully coupled three-dimensional (3D) chemistry-climate models (CCMs) are suitable tools to investigate the importance of these mutual effects. CCMs have been used to simulate the recent and future development of the chemical composition and the dynamics of the atmosphere (e.g. Rozanov et al., 2001; Austin, 2002; Schnadt et al., 2002; Nagashima et al., 2002; Pitari et al., 2002; Steil et al., 2003). The uncertainties and assessments of the currently available CCMs have been recently summarised by Austin et al. (2003).

In this study the CCM ECHAM4.L39(DLR)/CHEM (hereafter E39/C) is employed to assess the impact of solar zenith angles (SZAs) larger than $87.5^{\circ}$ for the chemistry and dynamics of the lower stratosphere, in particular at polar latitudes during winter and spring. It is well-known that the impact of photolysis on mixing ratios of chemical species depends on the maximum SZA allowed in model calculations. For example, an estimate by the $2 \mathrm{D}$ chemistry model MPIC for a specific case study at the $475 \mathrm{~K}$ isentropic level showed that the relative total ozone loss increased from $25 \%$ to $31 \%$ when the maximum SZA was raised from $90^{\circ}$ to $92^{\circ}$ (Krämer et al., 2003). Moldanova et al. (2002) showed that for some halogenated species and $\mathrm{NO}_{3}$, the photolysis beyond $90^{\circ}$ SZA may be of importance. Nevertheless, most CCMs neglect the impact of twilight for simplicity reasons, which certainly has an impact on chemical processes, especially during winter and spring near the edge of the polar night. 
This paper aims to quantify the effect of photolysis beyond 87.5 $\mathrm{SZA}$ in a fully coupled 3D CCM. In the next section the employed model system E39/C is briefly described, with special focus on the parameterisation of the photolysis up to $93^{\circ}$ SZA used here. The numerical simulations forming the basis for this investigation are briefly introduced. In Sect. 3 the model results are discussed, i.e., changes of photolysis frequencies, of ozone mixing ratios, and of related dynamical and chemical effects. Our conclusions are presented in the last section.

\section{Model description and design of experiments}

\subsection{Brief description of E39/C}

In this study the interactively coupled chemistry-climate model E39/C is employed. More detailed descriptions of the model are given in Hein et al. (2001) and Schnadt et al. (2002). The model horizontal resolution is T30. In the vertical, E39/C has 39 layers from the surface to the top layer centred at $10 \mathrm{hPa}$ (Land et al., 2002). The chemistry module CHEM (Steil et al., 1998) is based on the family concept. It describes relevant stratospheric and tropospheric $\mathrm{O}_{3}$ related homogeneous chemical reactions and heterogeneous chemistry on polar stratospheric clouds (PSCs) and sulphate aerosols, it does not consider bromine chemistry. E39/C includes an online feedback of chemistry, dynamics, and radiative processes. Chemical tracers are advected by the simulated winds. The net heating rates, in turn, are calculated using the actual 3D distributions of the radiatively active gases $\mathrm{O}_{3}, \mathrm{CH}_{4}, \mathrm{~N}_{2} \mathrm{O}, \mathrm{H}_{2} \mathrm{O}$, and CFCs. Climatological means of dynamical and chemical fields have been intensively validated with regards to other model results and to observations (e.g., Austin et al., 2003; Land et al., 2002; Hein et al., 2001).

2.2 Parameterisation of photolysis frequencies at large SZAs

The photolysis frequencies for SZAs less equal $87.5^{\circ}$ are calculated using the efficient method of Landgraf and Crutzen (1998) (see also Landgraf, 1998). The spectral range $(178.6 \mathrm{~nm} \leq \lambda \leq 752.5 \mathrm{~nm})$ relevant for the photo-chemistry of the troposphere and the middle atmosphere is divided into 8 wavelength intervals $I_{i}(i=1, \ldots, 8)$. For each interval, the photolysis frequency $J_{i, x}$ of a gas $x$ is calculated according to the equation:

$J_{i, x}=\int_{I_{i}} \sigma_{x}(\lambda) \Phi_{x}(\lambda) F(\lambda) d \lambda$,

where $\sigma_{x}(\lambda)$ is the absorption cross section, $\Phi_{x}(\lambda)$ the quantum yield, and $F(\lambda)$ the actinic flux in the interval $I_{i}$. In the spectral range of $202.0 \mathrm{~nm} \leq \lambda \leq 752.5 \mathrm{~nm}$, scattering at air molecules, aerosols, and clouds is not negligible. To include this efficiently, $J_{i, x}$ is calculated from precalculated photolysis frequencies for a purely absorbing atmosphere using Eq. (1) with high spectral resolution and a correction factor for the scattering effects:

$J_{i, x}=J_{i, x}^{a} \delta_{i}$

with

$\delta_{i}=\frac{F\left(\lambda_{i}\right)}{F^{a}\left(\lambda_{i}\right)}$.

$F^{a}\left(\lambda_{i}\right)$ and $F^{a}(\lambda)$ (see Eq. 4) are the actinic fluxes for a purely absorbing atmosphere for the wavelength $\lambda_{i}$ and $\lambda$ in the interval $I_{i}$. They are calculated using the Lambert-Beer absorption law:

$F^{a}(\lambda)=F_{0}(\lambda) \exp \left\{-\sum_{k} V_{k} \sigma_{k}(\lambda)\right\}$,

where $F_{0}(\lambda)$ is the spectral solar irradiance at the model top, $V_{k}$ is the slant column, and $\sigma_{k}$ is the absorbtion cross section of the $k$ th absorber $\left(\mathrm{O}_{2}\right.$ and $\left.\mathrm{O}_{3}\right)$. The correction factor $\delta_{i}$ is calculated online with a radiative transfer code (Zdundowski et al., 1980) at $\lambda_{i}$ of Landgraf and Crutzen (1998). It takes into account scattering as well as absorption due to air molecules, aerosols, clouds, and the Earth's surface albedo. The photolysis frequency is determined by the following equation:

$J_{x} \approx J_{1, x}^{a}+\sum_{i=2}^{8} J_{i, x}^{a} \delta_{i}$.

Here, $J_{1, x}^{a}$ is the photolysis frequency in the spectral range of the Schumann-Runge band $(178.6 \mathrm{~nm} \leq \lambda \leq 202.0 \mathrm{~nm})$, where $\mathrm{O}_{2}$ is a strong absorber and scattering can be neglected. So far, $J_{i, x}^{a}$ is calculated for an isothermal atmosphere. To account for the temperature dependence of $\sigma$ and $\Phi$, a correction function is applied. For further details of the parametrisation of $J_{i, x}^{a}$ and the temperature dependence see Landgraf (1998). Equations (1) to (5) are valid for SZAs up to $87.5^{\circ}$. For larger SZAs, the parameterisation of photolysis frequencies is done according to the laws of spherical geometry, where the actinic flux for a given wavelength depends on the SZA $\theta$ (Levy II, 1974). Röth $(1992,2002)$ introduced the following empirical formula for photolysis frequencies which includes very large zenith angles:

$J=J_{0} \cdot \exp [b(1-\sec (c \theta))]$,

with $J_{0}$ photolysis frequency for overhead sun and standard atmosphere at a certain altitude and empirical coefficients $b$ and $c$ which are tabulated for all species of interest. In E39/C we use a simplified version of this fit only for SZAs larger $87.5^{\circ}$. To account for the interactively calculated atmospheric quantities like ozone columns and reflection from clouds we adopt the J-value at SZA $87.5^{\circ}$, obtained with the Landgraf and Crutzen (1998) scheme and multiply that with a correction formular derived from Eq. (6):

$J_{>87.5}=J_{87.5} \cdot F_{\text {corr }}$ 
Table 1. The coefficients $b_{i}$ of Eq. (7) for the different species (channels), grouped by wavelength region most important for photolysis.

\begin{tabular}{rll}
\hline$b_{i}$ & species & region \\
\hline 1 & $\mathrm{O}_{3}\left(\rightarrow \mathrm{O}\left({ }^{3} \mathrm{P}\right)\right), \mathrm{NO}_{2}, \mathrm{NO}_{3}$ & $\mathrm{UV}-\mathrm{A}$ or visible \\
1.3 & $\mathrm{ClONO} 2, \mathrm{Cl}_{2} \mathrm{O}_{2}$ & UV-A \\
1.4 & $\mathrm{HOCl}$ & near UV-B \\
1.5 & $\mathrm{CH}_{2} \mathrm{O}(\mathrm{M}), \mathrm{N}_{2} \mathrm{O}_{5}, \mathrm{HNO}_{4}, \mathrm{CH}_{3} \mathrm{O}_{2} \mathrm{H}$ & UV-B \\
2 & $\mathrm{CH}_{2} \mathrm{O}(\mathrm{R}), \mathrm{H}_{2} \mathrm{O}_{2}$ & UV-B \\
3 & $\mathrm{O}_{3}\left(\rightarrow \mathrm{O}\left({ }^{1} \mathrm{D}\right)\right)$ & far UV-B \\
4 & $\mathrm{HNO}_{3}$ & far UV-B \\
5 & $\mathrm{O}_{2}, \mathrm{CFC}-11, \mathrm{CFC}-12, \mathrm{CCl}_{4}, \mathrm{CH}_{3} \mathrm{Cl}$, & \\
& $\mathrm{CH}_{3} \mathrm{CCl}_{3}, \mathrm{HCl}, \mathrm{H}_{2} \mathrm{O}, \mathrm{CO}_{2}, \mathrm{~N}_{2} \mathrm{O}, \mathrm{NO}$ & $\mathrm{UV}-\mathrm{C}$ \\
\hline
\end{tabular}

with

$F_{\text {corr }}=\exp \left[19.09 b_{i}\left(1-\frac{\theta}{87.5}\right)\right]$

The empirical coefficients $b_{i}$ in Eq. (8) are species dependent and listed in Table 1. They are derived from the ratio of Eq. (6) evaluated at $\theta$ equal $93^{\circ}$ and $87.5^{\circ}$ (with $F_{\text {corr }}=1$ for $\theta=87.5^{\circ}$ ). For SZAs larger $93^{\circ}$ night is assumed. This simplification can be justified because for polar stratospheric conditions mostly the on/off effect at sunrise/sunset matters. For SZAs between about $70^{\circ}$ and $87.5^{\circ}$ for the airmass factor $d(\theta)$ used in the photolysis calculation in Landgraf and Crutzen (1998) an empirical correction for the curvature of the atmosphere based on the Chapman-function is additionally applied (e.g. Lacis and Hansen, 1974):

$d(\theta)=\frac{35}{\sqrt{1224 \cos ^{2} \theta+1}}$.

For smaller SZAs $d(\theta)$ converges to $1 / \cos \theta$. This technique allows to calculate the photolysis rates online in a realistic atmospheric state, in which the SZA is time dependent.

\subsection{Model experiments}

Two timeslices representing atmospheric conditions for the early 1990s have been used, namely, a control scenario including SZAs up to $93^{\circ}$ (SZA93) and a sensitivity simulation which does not consider SZAs larger than 87.5 (SZA87.5) (see Sect. 2.2). Each timeslice has been integrated over 24 years under steady state conditions with the first four years taken as spin-up. For both model simulations, climatological mean sea surface temperatures (SST) are prescribed from observations for the years 1979 to 1994 (Gates, 1992). In addition, natural and anthropogenic $\mathrm{NO}_{\mathrm{x}}$ emissions are fixed at the surface. At the model top, mixing ratios of $\mathrm{NO}_{\mathrm{y}}$ and $\mathrm{CIX}$ $\left(=\mathrm{ClO}_{\mathrm{x}}+\mathrm{ClONO}_{2}+\mathrm{HCl}\right)$ are prescribed to account for higher altitude chemistry above the upper boundary. Moreover, the global mean values of the mixing ratios for the most relevant greenhouse gases $\mathrm{CO}_{2}, \mathrm{CH}_{4}$, and $\mathrm{N}_{2} \mathrm{O}$ are fixed at the lower
Table 2. Mixing ratios of greenhouse gases, inorganic chlorine, and $\mathrm{NO}_{\mathrm{x}}$ emissions of different natural and anthropogenic sources for the "1990" simulations (i.e., the SZA87.5 and the SZA93 run, respectively).

\begin{tabular}{lc}
\hline $\mathrm{CO}_{2}$ (ppmv) & 353 \\
$\mathrm{CH}_{4}$ (ppmv) & 1.69 \\
$\mathrm{~N}_{2} \mathrm{O}$ (ppbv) & 310 \\
$\mathrm{Cl}_{\mathrm{y}}$ (ppbv) & 3.4 \\
$\mathrm{NO}_{\mathrm{x}}$ lightning $(\mathrm{Tg}(\mathrm{N}) /$ year$)$ & 5.3 \\
$\mathrm{NO}_{\mathrm{x}}$ air traffic $(\mathrm{Tg}(\mathrm{N}) /$ year) & 0.6 \\
$\mathrm{NO}_{\mathrm{x}}$ surface (total) (Tg(N)/year) & 33.1 \\
$\mathrm{NO}_{\mathrm{x}}$ surface (industry, traffic) & 22.6 \\
$\mathrm{NO}_{\mathrm{x}}$ surface (soils) & 5.5 \\
$\mathrm{NO}_{\mathrm{x}}$ surface (biomass burning) & 5.0 \\
\hline
\end{tabular}

boundary for each scenario (Hein et al., 2001). They are specified according to observations for the year 1990. The specific boundary conditions are summarised in Table 2.

\section{Discussion of results}

\subsection{Changes of photolysis frequencies}

Neglecting large SZAs is associated with less photons at the day-night transition and in particular with a delay of daytime chemistry at the end of the polar night with significant effects for the destruction of ozone in the polar lower stratosphere. The photolysis of heterogeneously formed $\mathrm{Cl}_{2}$ at large SZAs after polar night initiates the catalytic ozone destruction by chlorine. Ozone depletion rates are highly related to the photolyis rates of $\mathrm{Cl}_{2} \mathrm{O}_{2}\left(\rightarrow \mathrm{O}_{2}+2 \mathrm{Cl}\right)$.

Figure 1 shows the absolute values of the photolysis frequencies of $\mathrm{Cl}_{2} \mathrm{O}_{2}$ for a single model year at $50 \mathrm{hPa}$ of the simulation SZA93. The structure of this field obviously reflects the importance of ozone as the dominant absorber: the photolysis frequencies are enhanced southward of $60^{\circ} \mathrm{S}$ between October and November (more than $1.2 \cdot 10^{-3} \mathrm{~s}^{-1}$ ), when ozone column values are still small and actinic fluxes differ significantly from zero. Including SZAs larger than $87.5^{\circ}$ leads to changes in the photolysis frequencies of $\mathrm{Cl}_{2} \mathrm{O}_{2}$ as is displayed in Fig. 2 for the $50 \mathrm{hPa}$ level. As expected, the most obvious changes are detected at the edge of the polar night (up to $0.6 \cdot 10^{-4} \mathrm{~s}^{-1}$ ) in both hemispheres. In the Southern Hemisphere absolute differences of the same order of magnitude are found in the polar region at the end of November, and correspond to about $5 \%$. The maximum changes in November are indirectly produced by reduced ozone in SZA93 (see Sect. 3.2). 


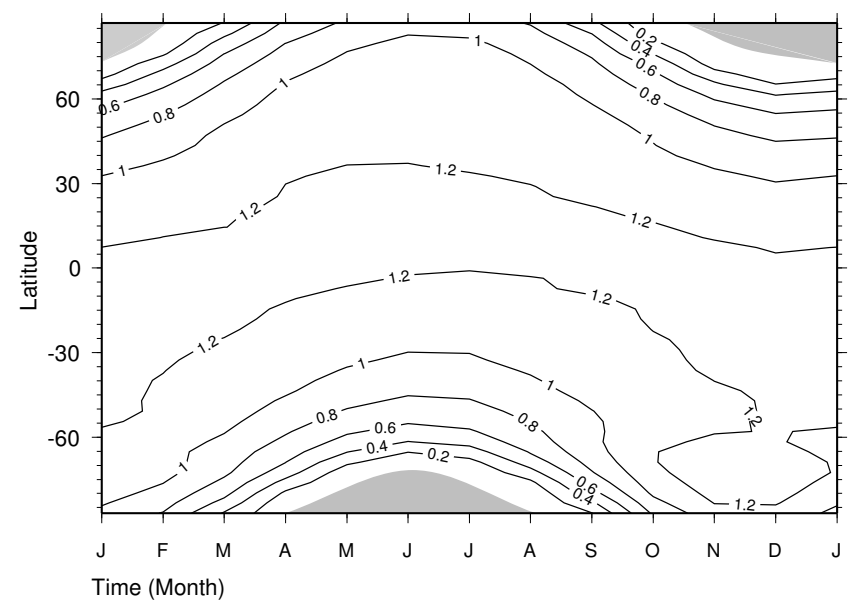

Fig. 1. Photolysis frequencies (noon values) of $\mathrm{Cl}_{2} \mathrm{O}_{2}\left[10^{-3} \mathrm{~s}^{-1}\right]$ at $50 \mathrm{hPa}$ in SZA93. Shaded areas indicate polar night, i.e., photolysis frequencies are zero. Letters at the $x$-axis denote the beginning months.

\subsection{Change of ozone}

\subsubsection{Ozone columns}

In order to evaluate the impact of twilight on upper tropospheric and lower stratospheric chemistry, we first compare the results of the climatological mean total ozone averaged over 20 simulated years including solar zenith angles up to $93^{\circ}$ (SZA93) (Fig. 3) to the values of a simulation that only considered SZAs up to $87.5^{\circ}$ (SZA87.5) (Fig. 4). A detailed comparison of the results presented in Figure 4 with observations (Bojkov et al., 1999) was presented in Hein et al. (2001). There, it was concluded that in the tropics as well as in the northern extra-tropics, the seasonal variations of simulated total ozone are in agreement with measurements, although the absolute total ozone values are overestimated by about 25 DU. In the southern extra-tropics, simulated ozone values are close to observations, but the seasonal variability of total ozone shows some noticeable differences. For example, the midlatitude modelled Austral spring maximum occurs earlier than observed (about 1 month) and the ozone hole season (i.e., total ozone locally less than 220 DU) lasts longer (i.e., until the beginning of December instead of end of October).

Figure 5 shows the differences between the modelled climatological mean total ozone fields (SZA93-SZA87.5). In the southern mid- and high latitudes between $30^{\circ} \mathrm{S}$ and $90^{\circ} \mathrm{S}$ the largest ozone difference values are simulated. These differences are statistically significant due to the relative low inter-annual variability. The ozone reduction is strongest south of $60^{\circ} \mathrm{S}$ between September and November due to the photon surplus in SZA93. The maximum differences are found in the centre of the polar vortex. At the end of September approximately 30 Dobson Units (DU) less ozone

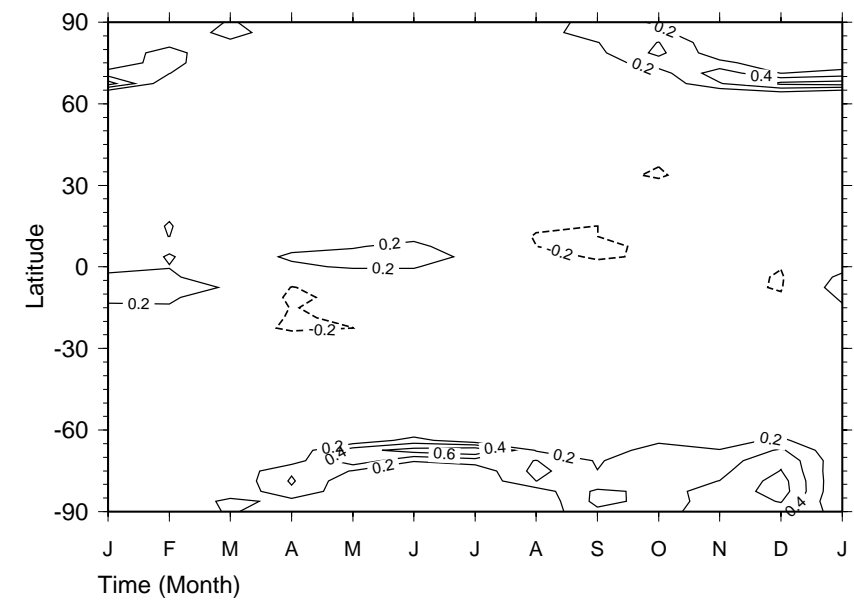

Fig. 2. Differences in photolysis frequencies (noon values) of $\mathrm{Cl}_{2} \mathrm{O}_{2}\left[10^{-4} \mathrm{~s}^{-1}\right]$ at $50 \mathrm{hPa}$ between SZA93 (Fig. 1) and SZA87.5. Positive differences indicate higher photolysis frequencies in SZA93.

are found in the SZA93 case. This corresponds to a maximum reduction of the ozone column over the south polar region of about $20 \%$ in the SZA93 run in comparison to the SZA87.5 simulation. A closer inspection indicates that in the SZA93 simulation ozone depletion starts earlier. Figure 6 shows the temporal development of total ozone at $70^{\circ} \mathrm{S}$ and $83^{\circ} \mathrm{S}$. For example, contemplating the $83^{\circ} \mathrm{S}$ curve, the ozone hole season appears 3 weeks earlier in SZA93 (i.e., first detection of total ozone values less than $220 \mathrm{DU}$ ) than in the SZA87.5 run and the minimum value is reached five days earlier. Both findings are an improvement with respect to observations. The lifetime of the ozone hole is about ten days longer in the SZA93 simulation. The latter result exhibits a slight degradation of model results with regards to the observations mentioned above. Similar changes are found at $70^{\circ} \mathrm{S}$, however the minimum values in SZA87.5 do not fall below 230 DU.

The statistically significant change of total ozone at Southern Hemisphere midlatitudes (about $20^{\circ} \mathrm{S}$ to $50^{\circ} \mathrm{S}$ ) cannot be directly due to $\mathrm{ClO}$-dimer photolysis. The main reason is additional ozone destruction by $\mathrm{NO}_{\mathrm{x}}$ catalysis in SZA93 (due to enhanced photolysis of $\mathrm{N}_{2} \mathrm{O}_{5}$ at a longer day), which is important in the altitude range between 10 and $100 \mathrm{hPa}$ in mid- and high latitudes. For example, in midlatitudes of the Southern Hemisphere at $50 \mathrm{hPa} \mathrm{NO}_{\mathrm{x}}$ is enhanced by between 10 and 50 pptv in the SZA93 simulation, which is approximately $10 \%$ (not shown). Brühl and Crutzen (2000) pointed out that although in summer net chemical ozone production occurs in the latitude region between the subtropical barrier and about $50^{\circ}$, total ozone declines in this region because of exchange with the net chemical destruction regions (which are larger for the SZA93 case) in high latitudes and in the troposphere. Here, we can conclude that the 


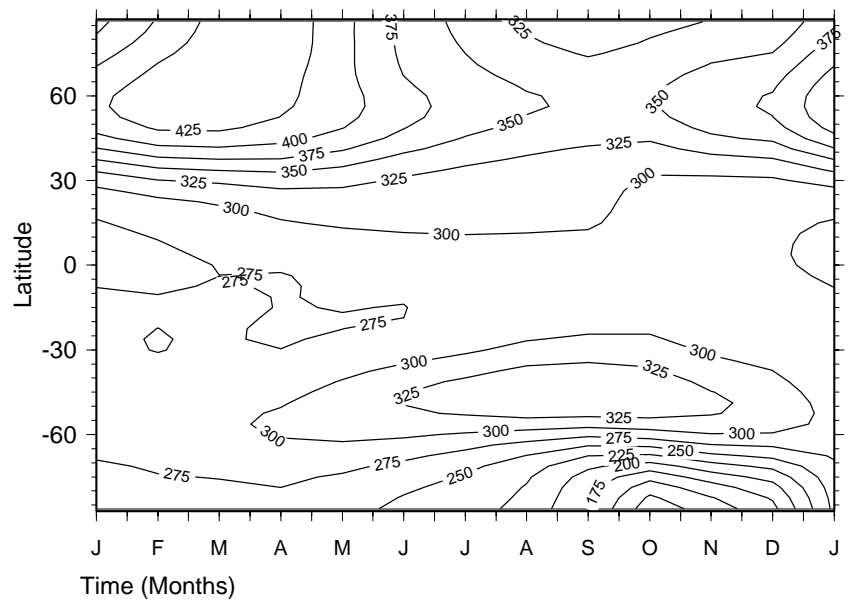

Fig. 3. Modelled climatological zonal mean total ozone (in Dobson Units, DU) taking in account SZAs up to $93^{\circ}$ (SZA93). The model results are averaged over 20 simulated years.

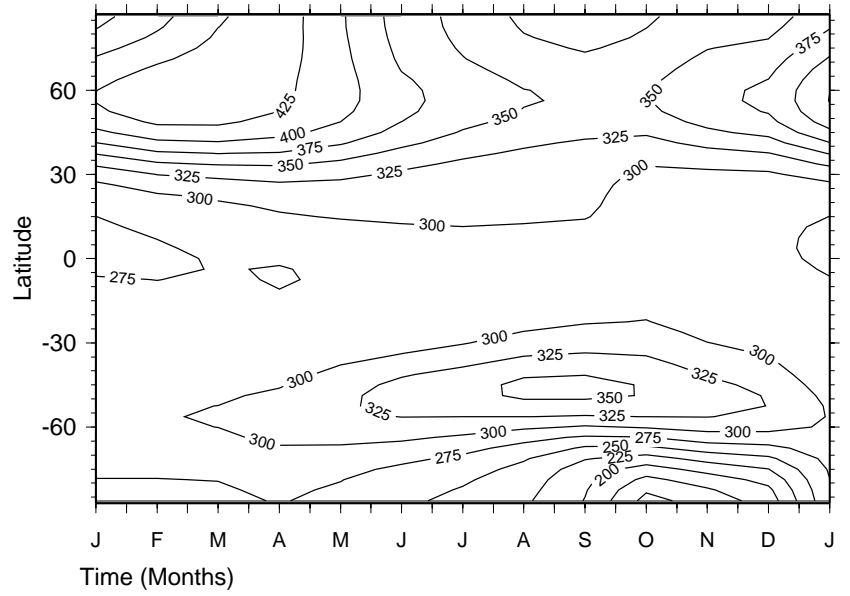

Fig. 4. Same as in Fig. 5, but considering SZAs up to $87.5^{\circ}$ only (SZA87.5).

Southern Hemisphere midlatitude total ozone values of the SZA93 simulation are in better agreement with observations than those of SZA87.5.

In high latitudes of the Northern Hemisphere total ozone is moderately increased by about $2 \%$ to $4 \%$ between February and the middle of March. Due to the high inter-annual dynamic variability of the Northern Hemisphere polar stratosphere, these changes are not statistically significant. This does not principally exclude that individual cold Northern Hemisphere model winters experience similar large SZA effects as is generally found in the Southern Hemisphere. Several papers showed that photochemical box model calculations cannot reproduce observed ozone loss rates during cold Arctic Januaries (e.g. Becker et al., 1998; Hansen and Chipperfield, 1999; Rex et al., 2003). Although it seems that the missing ozone loss mechanism is important at large SZAs

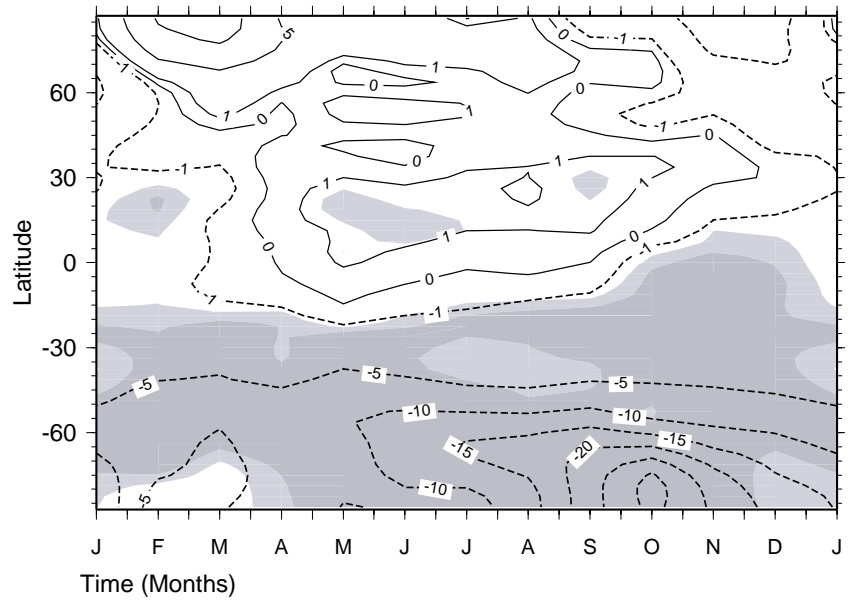

Fig. 5. Changes of total ozone (in DU) between SZA93 and SZA87.5. Negative (positive) values indicate lower (higher) values in SZA93. Dark (light) shaded areas indicate the 99\% (95\%) significance level ( $t$-test).
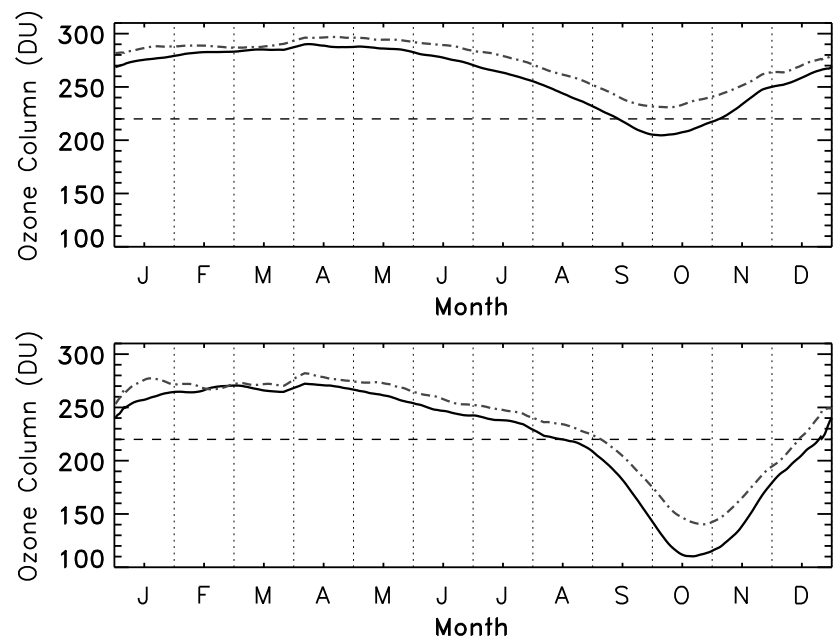

Fig. 6. Temporal development of climatological zonal mean total ozone columns (in DU) at $70^{\circ} \mathrm{S}$ (top) and at $83^{\circ} \mathrm{S}$ (bottom). Dashed (solid) lines denote results from the simulation SZA87.5 (SZA93).

and low temperatures, the discrepancies between the model results and observations cannot be solely explained due to the models restricting the photolysis calculations to SZAs of less than $90^{\circ}$, at best it can explain a small part of it.

In tropical regions, as well as in midlatitudes of the Northern Hemisphere only small changes occur due to larger SZAs. The differences in the tropics are about $1 \%$ (approximately $3 \mathrm{DU}$ ), they are partly statistically significant. This can be explained considering the mean ozone value of about $275 \mathrm{DU}$ in the tropics and the very low inter-annual dynamic variability in these regions. 

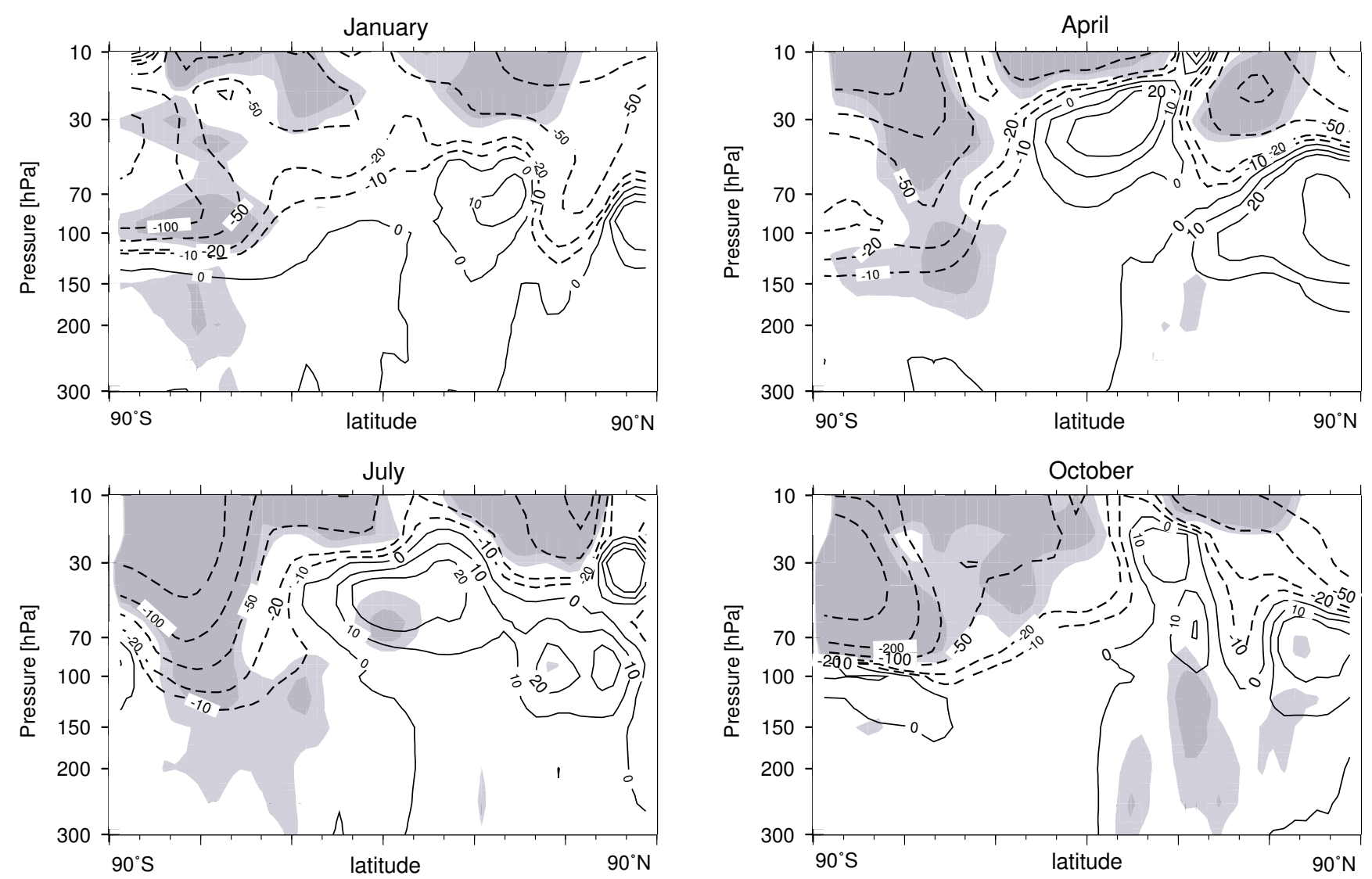

Fig. 7. Changes of climatological zonal mean ozone mixing ratios (ppbv) depending on altitude and latitude for January, April, July, and October. Negative (positive) values indicate lower (higher) values in SZA93. Heavy (light) shaded areas indicate the $99 \%$ (95\%) significance level (t-test). Isolines are plotted on a logarithmic scale: $-500,-200,-100,-50,-20,-10,0,10,20,50,100$.

\subsubsection{Zonal mean ozone difference}

To investigate the modelled ozone changes due to large SZAs in more detail, differences of zonal mean ozone mixing ratios are presented in Fig. 7 showing changes for January, April, July, and October. Nearly no changes of ozone mixing ratios are calculated below $150 \mathrm{hPa}$, most of the differences occur in the stratosphere. Ozone mixing ratios significantly decrease during southern spring at levels between $100 \mathrm{hPa}$ and the model top. In SZA93, additional ozone decreases are mainly detected inside the polar vortex (south of $\sim 65^{\circ} \mathrm{S}$ ). At the centre of the polar vortex, between $70 \mathrm{hPa}$ and $10 \mathrm{hPa}$ an ozone reduction of more than $-500 \mathrm{ppbv}$ is found in October. As already noted, sun rays enter the model atmosphere region between $65^{\circ} \mathrm{S}$ and the South pole earlier in spring in SZA93 than in SZA87.5. The photon surplus at the edge of the polar night is responsible for the increased ozone destruction (see Sect. 3.1).

At midlatitudes and in the tropical regions, ozone decreases are larger at the upper model levels than at lower levels. Ozone differences up to $-50 \mathrm{ppbv}$ are simulated in January between $60^{\circ} \mathrm{S}$ and $10^{\circ} \mathrm{S}$ and between $30 \mathrm{hPa}$ and
$10 \mathrm{hPa}$. Because of the ozone reduction at the upper model levels, more sunlight penetrates down to lower atmospheric layers which has an impact on dynamics (temperature) and chemistry. Ozone differences are small in the equatorial regions. In April and July, ozone concentrations are larger in SZA93 by about 20 ppbv in comparison to SZA87.5. This is probably due to a slightly distinct circulation pattern producing small differences in the climatological mean ozone distributions in both model experiments (Sect. 3.3).

The Arctic stratosphere shows some modifications in ozone mixing ratios, however, these changes are mostly not statistically significant due to the high dynamic inter-annual variability of the Northern Hemisphere. The described ozone changes caused by considering large SZAs are due to dynamical and chemical effects. In the next two sections we will quantify some of these effects in E39/C.

\subsection{Change of dynamics}

Statistically significant temperature differences between the SZA93 and the SZA87.5 simulations are mainly found in the extra-tropical Southern Hemisphere lower stratosphere 


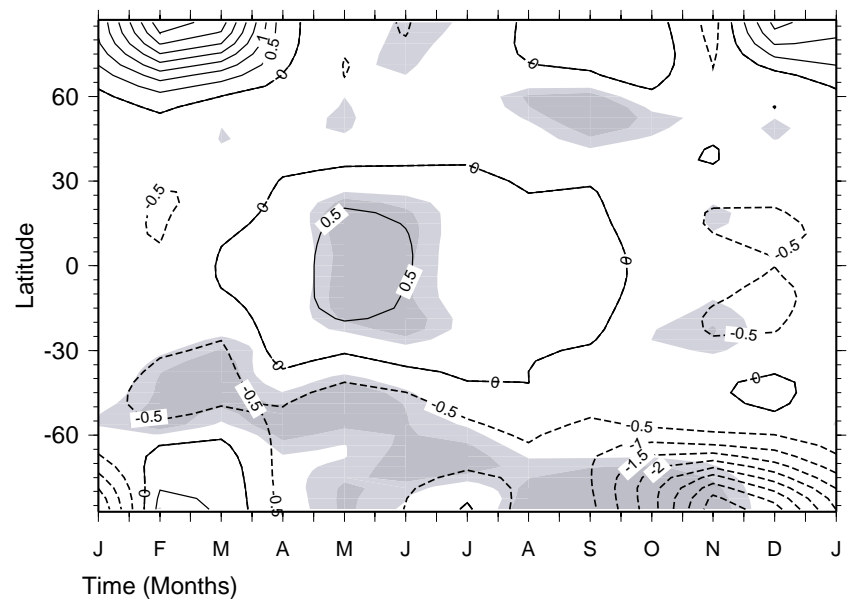

Fig. 8. Changes of climatological mean temperatures (K) at $50 \mathrm{hPa}$ between SZA93 and SZA87.5. Negative (positive) values indicate lower (higher) values in SZA93. Heavy (light) shaded areas indicate the $99 \%$ (95\%) significance level (t-test).

(between 10 and $100 \mathrm{hPa}$ ). Figure 8 shows the differences for the $50 \mathrm{hPa}$ pressure level. The largest values occur during polar spring (up to $-4 \mathrm{~K}$ ) indicating that the SZA93 simulation produces colder conditions there. Near the edge of the Southern Hemisphere polar vortex the SZA93 run shows a cooling between $-0.5 \mathrm{~K}$ and $-1 \mathrm{~K}$. These temperature differences can be easily related to the detected changes of the ozone column between the two model runs discussed in the last two sections (Fig. 5). In SZA93, the stratosphere is colder in regions with reduced ozone with regards to the SZA87.5 run. In the Northern Hemisphere, higher temperatures are found in the SZA93 case in later winter and early spring in the polar region due to the increase of ozone. As mentioned before, these differences are statistically not significant due to the high dynamic inter-annual variability in this time of the year and region. Therefore, these temperature differences are fortuitous and cannot be interpreted. The increase of ozone in the tropics in the SZA93 run (i.e., about 2 DU in May and June) produces a warming of approximately $0.7 \mathrm{~K}$. Although these differences are small they are statistically significant because the inter-annual variability in the equatorial region is very small.

The differences in the temperature fields result in corresponding differences in the mean zonal wind fields (not shown). However, these are statistically not significant, neither in the Southern nor in the Northern Hemisphere. For example, the Southern Hemisphere polar night jet is stronger in the SZA93 simulation by about $2 \mathrm{~m} / \mathrm{s}$. In the Northern Hemisphere, the wintertime stratospheric polar vortex is weaker (about $-2 \mathrm{~m} / \mathrm{s}$ ) in SZA93. These results are consistent with the formerly discussed ozone and temperature differences.

Altogether it can be summarised that the mean climatological temperature conditions are clearly different in the po-

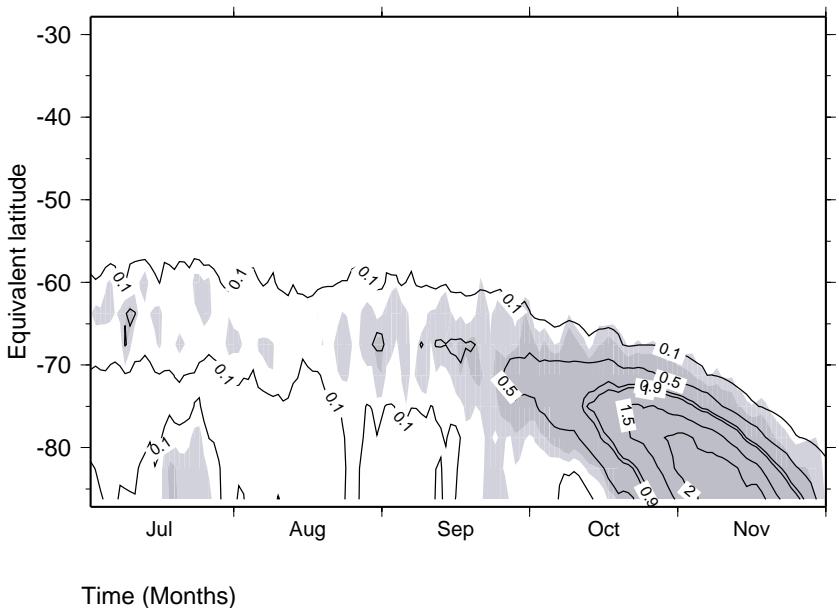

Fig. 9. Changes of the climatological zonal mean PSC I-NAT (ppbv) at $50 \mathrm{hPa}$ in the Southern Hemisphere between SZA93 and SZA87.5. Model data are transformed to the PV-coordinate system. Positive (negative) values indicate higher (lower) values in the SZA93 simulation. Heavy (light) shaded areas indicate the $99 \%$ (95\%) significance level (t-test).

lar Southern Hemisphere. This has a strong impact on the temperature-dependent chemistry, in particular on the formation of polar stratospheric clouds (PSCs) and thus on heterogeneous ozone destruction (see Sect. 3.4).

\subsection{Change of chemistry}

To estimate the importance of considering SZAs larger than $87.5^{\circ}$ on stratospheric chemistry in a fully coupled 3D CCM, some chemical species have been analysed which are especially relevant for polar chemistry. In the following, we concentrate on Southern Hemisphere winter and spring conditions where the differences of climatological mean fields between the two model simulations are most obvious. For an appropriate presentation of the results, a coordinate transformation is carried out from the standard coordinate system to a description employing equivalent potential vorticity (PV) coordinates (e.g. Butchart and Remsberg, 1986; Manney et al., 1994). Here, the centre of the coordinate system is chosen to be the centre of the polar vortex. Isentropic contours are then used to define equivalent latitudes, for which 'zonal means' with respect to the centre of the polar vortex are computed.

As shown in the previous section, stratospheric temperatures are reduced if SZAs up to $93^{\circ}$ are considered. Main temperature differences between the SZA93 run and the SZA87.5 simulation are found in springtime inside the polar vortex. This favours the formation of PSCs in the SZA93 run. In this region the conditions are most favourable for heterogenous chemistry on PSC surfaces during the polar night. Figures 9 and 10 show the differences of PSC I and II mixing ratios between the two simulations at $50 \mathrm{hPa}$. Obviously, a statistically significant increase of NAT and ice particles 


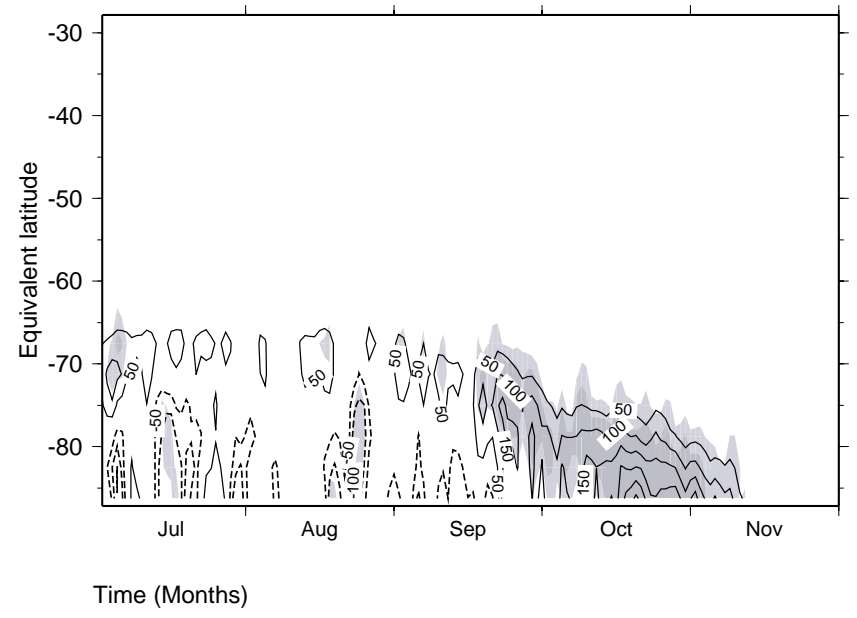

Fig. 10. As Fig. 9, but for PSC II-ICE (pptv).

can be found in SZA93 reflecting the differences in temperatures. Both figures illustrate that the enhancement is firstly seen at the inner edge of the polar vortex in mid-winter. Maximum differences are shifted towards higher latitudes with time with the size of the polar vortex becoming smaller.

The photon surplus increases the photolysis of chlorine compounds $\left(\mathrm{Cl}_{2} \mathrm{O}_{2}, \mathrm{Cl}_{2}, \mathrm{HOCl}\right.$, and $\left.\mathrm{ClONO}_{2}\right)$ in SZA93. $\mathrm{ClO}$ and $\mathrm{Cl}$ radicals are released and enhance the destruction of ozone through catalytic reactions, especially the socalled "dimer cycle" involving $\mathrm{Cl}_{2} \mathrm{O}_{2}$ which is quadratic in $\mathrm{ClO}$. Figure 11 shows the differences in $\mathrm{ClO}_{\mathrm{x}}$ at the $50 \mathrm{hPa}$ pressure level. An enhanced activation of chlorine is found inside the polar vortex between July and November. Maximum difference values are about $0.5 \mathrm{ppbv}$, these differences are statistically significant. An exception is found in the core region of the polar vortex in the second half of October where a decrease of $\mathrm{ClO}_{\mathrm{x}}$ (up to $-0.3 \mathrm{ppbv}$ ) is detetected in the SZA93 run. This can be explained considering the related differences of $\mathrm{ClONO}_{2}$ and $\mathrm{HCl}$ which are displayed in Figs. 12 and 13. Reduced $\mathrm{ClONO}_{2}$ mixing ratios are found in the SZA93 run inside the polar vortex between mid October and mid November while $\mathrm{HCl}$ is increased there. This behaviour can be explained as follows: the chemical reaction $\mathrm{Cl}+\mathrm{O}_{3} \rightarrow \mathrm{ClO}+\mathrm{O}_{2}$ determines the rate of formation of $\mathrm{ClONO}_{2}$. Since in the model during this time only little ozone ( 0.5 ppmv or less) is available, less chlorine monoxide $(\mathrm{ClO})$ is produced which can be transformed to $\mathrm{ClONO}_{2}$ $\left(\mathrm{ClO}+\mathrm{NO}_{2}+\mathrm{M} \rightarrow \mathrm{ClONO}_{2}+\mathrm{M}\right)$. In case of low ozone the ratio $\mathrm{Cl} / \mathrm{ClO}$ is large leading to fast re-formation of the $\mathrm{HCl}$ reservoir $\left(\mathrm{Cl}+\mathrm{CH}_{4} \rightarrow \mathrm{HCl}+\mathrm{CH}_{3}\right)$. Thus, the chlorine atoms formed by the photolysis of $\mathrm{Cl}_{2}$ and $\mathrm{Cl}_{2} \mathrm{O}_{2}$ after mid October do not primarily react with ozone, but with methane which produce an increase of $\mathrm{HCl}$. This model behaviour is in agreement with box model calculations and HALOE observations (Grooß et al., 1997; Steil et al., 2003). Although the results of both E39/C simulations show a real-

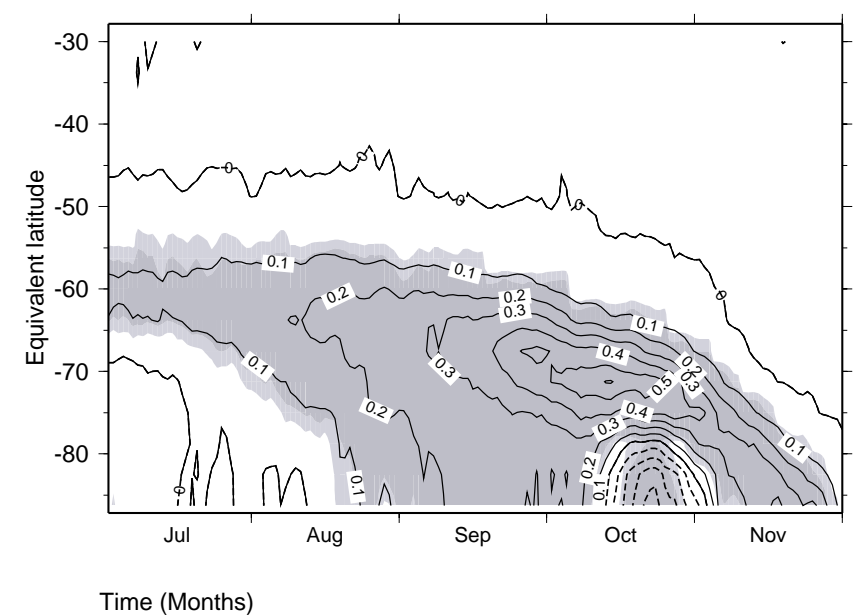

Fig. 11. As Fig. 9, but for $\mathrm{ClO}_{\mathrm{x}}$ (ppbv).

istic behaviour with regards to the re-formation of the chlorine reservoirs $\mathrm{HCl}$ and $\mathrm{ClONO}_{2}$, i.e., $\mathrm{ClO}_{\mathrm{x}}$ is first converted towards $\mathrm{HCl}$, the SZA93 simulation produces improved results concerning the time of re-formation ( 2 weeks earlier), which means that they are closer to the analyses of observations given by Grooß et al. (1997) and Steil et al. (2003). For completeness it is worthwhile mentioning that the collar of $\mathrm{ClONO}_{2}$ is enhanced in the SZA93 simulation, as expected.

\section{Conclusions}

The current sensitivity study with the fully coupled CCM E39/C has shown that photolysis reactions during twilight have a non-negligible impact on the lower stratosphere, although the actinic fluxes for SZAs larger $87.5^{\circ}$ are small. Considering climatological mean values, statistically significant effects on the chemistry and dynamics of the lower stratosphere are mainly found in higher latitude regions of the Southern Hemisphere during winter and spring. Obvious changes are also detected in midlatitudes of the Southern Hemisphere which can be partially attributed to enhanced ozone destruction in the lower stratosphere by enhanced $\mathrm{NO}_{\mathrm{x}}$ catalysis in the SZA93 simulation. Due to the high dynamic variability of the Northern Hemisphere lower and middle stratosphere, similar effects cannot be detected there. Certainly, in individual cold Northern Hemisphere winter periods with a stable polar vortex analogous results would be obtained. The detected changes of dynamic and chemical values in the tropics and in midlatitudes of the Northern Hemisphere can be neglected.

In E39/C, the small surplus of photons for SZAs larger $87.5^{\circ}$ produces a different climatological mean ozone distribution. In the SZA93 run, ozone destruction is stronger, in particular in the southern extra-tropics. The maximum effect is found near the South Pole in spring. Due to reduced ozone 


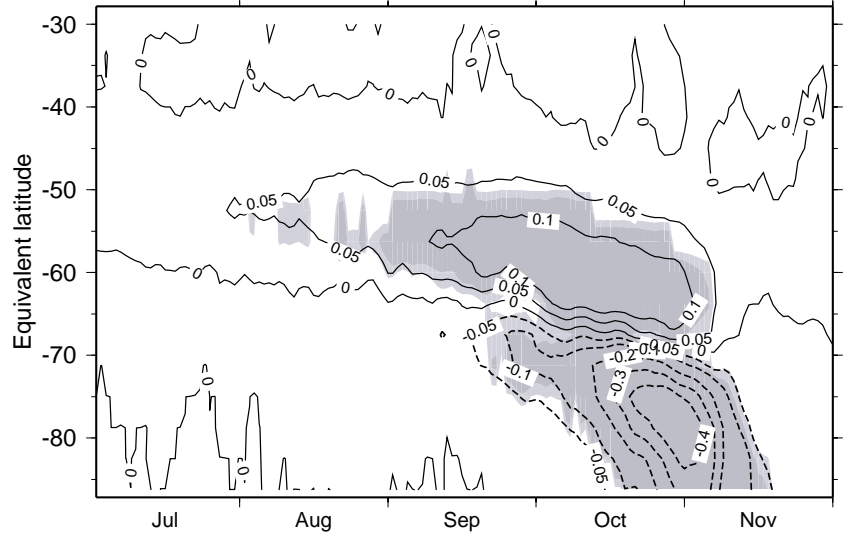

Time (Months)

Fig. 12. As Fig. 9, but for $\mathrm{ClONO}_{2}$ (ppbv).

concentrations, less UV radiation is absorbed in SZA93. This cools down the lower stratosphere, causing an increased formation of PSCs. Consequently, heterogeneous chemical reactions on PSC particles, subsequent chlorine activation, and ozone destruction are intensified. In the Southern Hemisphere, this results in a total additional reduction of the climatological mean total ozone column of approximately $20 \%$ and an extension of the "ozone hole season" of about four weeks.

For a valuation of the results presented in this paper it must be considered that neither the simulation SZA87.5 nor SZA93 do include large SZA photons (larger $90^{\circ}$ ) for the calculation of heating rates. This could perhaps partially compensate increased ozone destructions. An assessment of this supplementary effect, which is expected to be small, requires significant changes in the model and extra model runs. This is planned to be done in forthcoming studies with E39/C. Another effect to be considered in future simulations is the near infrared photolysis of $\mathrm{HO}_{2} \mathrm{NO}_{2}$ via excitation of purely vibrational modes at wavelengths larger than $760 \mathrm{~nm}$, which works also at low sun conditions in high latitude winter. It turned out to be important for the partitioning of reactive nitrogen in the lower stratosphere and upper troposphere and to reduce discrepancies between observations and models (Salawitch et al., 2002; Evans et al., 2003; Donaldson et al., 2003).

This study is the first assessment using a 3D CCM to quantify the effects of large SZAs on the dynamics and chemistry of the lower stratosphere. It shows that the photolysis for SZAs larger $87.5^{\circ}$ is relevant especially in polar regions and cannot be neglected for simplicity reasons as done in most other CCMs. Although the results of the SZA93 simulation give no overall improvement of the ozone and the temperature climatology of E39/C, this does not mean that considering large SZAs for photodissociation is a step in the wrong direction. Rather it points to further model deficien-

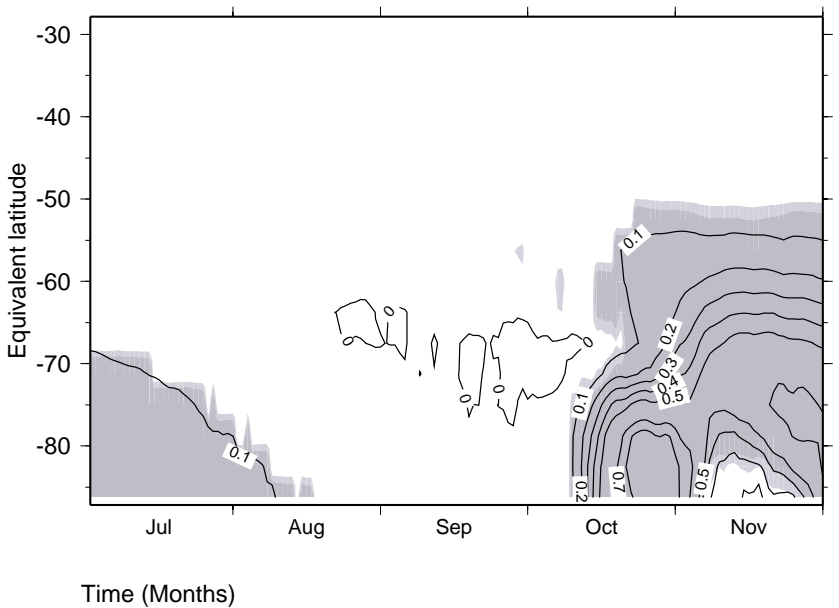

Fig. 13. As Fig. 9, but for $\mathrm{HCl}$ (ppbv). The maximum value (end of October) is about 0.9 ppbv.

cies. Since E39/C is an interactively coupled, non-linear model, it is difficult to identify individual weaknesses and their importance for the entire model system. Therefore, the only way to improve such models is further, continuous development and completion of relevant processes, to obtain a model as realistic as possible.

Acknowledgements. The authors thank Ernst-Peter Röth for helpful comments. The work was partly supported by the German Government (BMBF) within the scope of the AFO 2000 project KODYACS.

\section{References}

Austin, J.: A three-dimensional coupled chemistry-climate model simulation of past stratospheric trends, J. Atmos. Sci., 59, 218232, 2002.

Austin, J., Shindell, D., Beagley, S. R., Brühl, C., Dameris, M., Manzini, E., Nagashima, T., Newman, P., Pawson, S., Pitari, G., Rozanov, E., Schnadt, C., and Shepherd, T. G.: Uncertainties and assessments of chemistry-climate models of the stratosphere, Atmos. Chem. Phys., 3, 1-27, 2003.

Becker, G., Müller, R., McKenna, D. S., Rex, M., and Carslaw, K. S.: Ozone loss rates in the Arctic stratosphere in the winter 1991/92: Model calculations compared with Match results, Geophys. Res. Lett., 25, 4325-4328, 1998.

Bojkov, R. D., Hudson, R., Bishop, L., Fioletov, V. E., Russell III., J. M., Stolarski, R., Uchino, O., and Zerefos, C.: Ozone variability and trends, in: Scientific Assessment of Ozone Depletion: 1998, WMO Global Ozone Research and Monitoring Project, Report No. 44, ISBN 92-807-1722-7, 4.1-4.55, 1999.

Brühl, C. and Crutzen, P. J.: $\mathrm{NO}_{\mathrm{x}}$-catalyzed ozone destruction and $\mathrm{NO}_{\mathrm{x}}$ activation at midlatitudes to high latitudes as the main cause of the spring to fall ozone decline in the Northern Hemisphere, J. Geophys. Res., 105, 12 163-12 168, 2000. 
Butchart, N. and Remsberg, E. E.: The area of the stratospheric polar vortex as a diagnostic for tracer transport on an isentropic surface, J. Atmos. Sci., 43, 1319-1339, 1986.

Donaldson, D. J., Tuck, A. F., and Vaida, V.: Atmospheric photochemistry via vibrational overtone absorption, Chem. Rev., CR0206519, in press, 2003.

Evans, J. T., Chipperfield, M. P., Oelhaf, H., Stowasser, M., and Wetzel, G.: Effect of near-IR photolysis of $\mathrm{HO}_{2} \mathrm{NO}_{2}$ on stratospheric chemistry, Geophys. Res. Lett., 30, 1223, doi:10.1029/2002GL016470, 2003.

EC (European Commission): Ozone-climate interactions, Air Pollution Research Report No. 81, EUR 20623, ISBN 92-894-56191, 143 pp., 2003.

Gates, W. L.: AMIP: The atmospheric model intercomparison project, Bull. Amer. Meteor. Soc., 73, 1962-1970, 1992.

Grooß, J.-U., Bradley, R. B., Crutzen, P. J., Grose, W. L., and Russell III, J. M.: Re-formation of chlorine reservoirs in southern hemisphere polar spring, J. Geophys. Res., 102, 13 141-13 152, 1997.

Hansen, G. and Chipperfield, M. P.: Ozone depletion at the edge of the Arctic polar vortex 1996/1997, J. Geophys. Res., 104, 18371845, 1999.

Hein, R., Dameris, M., Schnadt, C., Land, C., Grewe, V., Köhler, I., Ponater, M., Sausen, R., Steil, B., Landgraf, J., Brühl, C.: Results of an interactively coupled atmospheric chemistry-general circulation model: Comparison with observations, Ann. Geophysicae, 19, 435-457, 2001.

IPCC (Intergovernmental Panel on Climate Change): Climate change 2001; the scientific basis, contribution of working group I to the Third Assessment Report of IPCC, edited by Houghton, J. T., Ding, Y., Griggs, D. J., Noguer, M., van der Linden, P. J., Dai, X., Maskell, K., and Johnson, C. A., Cambridge University Press, 2001.

Krämer, M., Müller, Ri., Bovensmann, H., Burrows, J., Brinkmann, J., Röth, E. P., Grooß, J.-U., Müller, Ro., Woyke, T., Ruhnke, R., Günther,G., Hendricks, J., Lippert, E., Carslaw, K. S., Peter, T., Zieger, A., Brühl, C., Steil, B., Lehmann, R., and McKenna, D. S.: Intercomparison of stratospheric chemistry models under polar vortex conditions, J. Atmos. Chem., 45, 51-77, 2003.

Lacis, A. A. and Hansen, J. E.: A parameterization for the absorption of solar radiation in the Earth's atmosphere, J. Atmos. Sci., 31, 118-133, 1974.

Land, C., Feichter, J., and Sausen, R.: Impact of vertical resolution on the transport of passive tracers in the ECHAM4 model, Tellus, 54B, 344-360, 2002.

Landgraf, J.: Modellierung photochemisch relevanter Strahlungsvorgänge in der Atmosphäre unter Berücksichtigung des Einflusses von Wolken, Fachbereich Physik, Universität Mainz, Ph.D. thesis, 1998.

Landgraf, J. and Crutzen, P. J.: An efficient method for online calculations of photolysis and heating rates, J. Atmos. Sci., 55, 863878, 1998.

Levy II, H.: Photochemistry of the troposphere, Adv. Photochem., 9, 369-524, 1974.
Manney, G. L., Zurek, R. W., Gelman, M. E., Miller, A. J., Nagatani, R.: The anomalous Arctic lower stratospheric polar vortex, Geophys. Res. Lett., 21, 2405-2408, 1994.

Moldanova, J., Bergström, R., and Langner, J.: A photolysis scheme for photochemical modelling of the troposphere and lower stratosphere, A contribution to the EUROTRAC-2 subproject GLOREAM, Proceedings from the EUROTRAC-2 Symposium, Garmisch-Partenkirchen, ISBN 3-8236-1385-5, 2002.

Nagashima, T., Takahashi, M., Takigawa, M., and Akiyoshi, H.: Future development of the ozone layer calculated by a general circulation model with fully interactive chemistry, Geophys. Res. Lett., 29, doi:10.1029/2001GL014026, 2002.

Pitari, G., Manzini, E., Rizi, V., and Shindell, D.: Impact of future climate and emission changes on stratospheric aerosols and ozone, J. Atmos. Sci., 59, 414-440, 2002.

Rex, M., Salawitch, R. J., Santee, M. L., Waters, J. W., Hoppel, K., and Bevilacqua, R.: On the unexplained stratospheric ozone losses during cold Arctic Januaries, Geophys. Res. Lett., 30, 1008, doi:10.1029/2002GL016008, 2003.

Röth, E.-P.: A fast algorithm to calculate the photonflux in optically dense media for use in photochemical models, Ber. Bunsenges. Phys. Chem., 96, 417-420, 1992.

Röth, E.-P.: Description of the anisotropic radiation transfer model ART to determine photodissociation coefficients, Institut für Stratosphärische Chemie, Forschungszentrum Jülich, 2002.

Rozanov, E. V., Schlesinger, M. E., and Zubov, V. A.: The Universtiy of Illinois at Urbana-Champaign three-dimensional stratosphere-troposphere general circulation model with interactive ozone photochemistry: Fifteen-year control run climatology, J. Geophys. Res., 106, 27 233-27 254, 2001.

Salawitch, R. J., Wennberg, P. O., Toon, G. C., Sen, B., and Blavier, J.-F.: Near IR photolysis of $\mathrm{HO}_{2} \mathrm{NO}_{2}$ : Implications for $\mathrm{HO}_{\mathrm{X}}$, Geophys. Res. Lett., 29, doi:10.1029/2002GL015006, 2002.

Schnadt, C., Dameris, M., Ponater, M., Hein, R., Grewe, V., and Steil, B.: Interaction of atmospheric chemistry and climate and its impact on stratospheric ozone, Clim. Dyn., 18, 501-517, 2002.

Steil, B., Dameris, M., Brühl, C., Crutzen, P. J., Grewe, V., Ponater, M., and Sausen, R.: Development of a chemistry module for GCMs: first results of a multiannual integration, Ann. Geophysicae, 16, 205-228, 1998.

Steil, B., Brühl, C., Manzini, E., Crutzen, P. J., Lelieveld, J., Rasch, P. J., Roeckner, E., and Krüger, K.: A new interactive chemistry climate model. 1: Present day climatology and interannual variability of the middle atmosphere using the model and 9 years of HALOE/UARS data, J. Geophys. Res., 108, 4290, doi:10.1029/2002JD002971, 2003.

WMO (World Meteorological Organisation): Scientific Assessment of Ozone depletion: 2002, Global Ozone Research and Monitoring Project, Report No. 47, ISBN 92-807-2261-1, 498 pp., 2003.

Zdundowski, W. G., Welch, R. M., and Korb, G.: An investigation of the structure of typical two-stream methods for calculation of solar fluxes and heating rates in clouds, Beitr. Phys. Atmosph., 53, 147-166, 1980. 